\title{
Pre-existing cerebrovascular disease and poor outcomes of COVID-19 hospitalized patients: a meta-analysis
}

\author{
Urvish Patel $^{1} \cdot$ Preeti Malik $^{1}$ (D $\cdot$ Dhaivat Shah $^{1} \cdot$ Achint Patel $^{1} \cdot$ Mandip Dhamoon $^{2} \cdot$ Vishal Jani $^{3}$
}

Received: 19 June 2020 / Revised: 31 July 2020 / Accepted: 4 August 2020 / Published online: 8 August 2020

(c) Springer-Verlag GmbH Germany, part of Springer Nature 2020

\begin{abstract}
Background Due to pro-inflammatory and hypercoagulation states, COVID-19 infection is believed to increase the risk of stroke and worsen the outcomes of the patients having pre-existing cerebrovascular diseases (CeVD). There is limited literature on prevalence of pre-existing CeVD in COVID-19 patients, and outcomes are unknown. The objective of this meta-analysis is to evaluate the outcomes of COVID-19 patients with pre-existing CeVD.

Methods English full-text-observational studies having data on epidemiological characteristics of COVID-19 patients were identified searching PubMed, Web of Science, and Scopus using MeSH-terms COVID-19 OR coronavirus OR SARSCoV-2 OR 2019-nCoV from December 1, 2019 to April 30, 2020. Studies having CeVD or stroke as one of the pre-existing comorbidities and described outcomes including intensive care unit (ICU) admission, mechanical ventilation utilization, and mortality were selected with consensus of three reviewers. Following MOOSE protocol, 11 studies were included. The pooled prevalence of $\mathrm{CeVD}$ and outcomes were calculated. Meta-regression was performed, and correlation coefficient $(r)$ and odds ratio (OR) were estimated to evaluate the effects of pre-existing CeVD on outcomes of COVID-19 patients. Meta-analysis with random-effects model was used to calculate OR along with its $95 \% \mathrm{CI}$ from the studies containing data on composite poor outcome.

Results Out of 8/11 studies showing data on mortality and mechanical ventilation, and 7/11 on ICU admission, pooled prevalence of pre-existing CeVD was 4.4\% (244/4987). In age-adjusted meta-regression analysis, pre-existing CeVD was associated with ICU admission [ $r$ : 0.60; OR: 1.82 (1.25-2.69)], mechanical ventilation [r: 0.29; OR: 1.33 (1.09-1.63)], and mortality [ $r$ : 0.35; OR: 1.42 (1.14-1.77)] amongst COVID-19 hospitalizations. 9/11 studies reported data on binary composite outcomes, the pooled prevalence of pre-existing CeVD was 4.3\% (155/3603) and 7.46\% (83/1113) amongst COVID-19 hospitalizations and COVID-19 hospitalization-related poor outcomes, respectively. In meta-analysis, COVID-19 patient with pre-existing CeVD had 2.67-fold (1.75-4.06) higher odds of poor outcomes.

Conclusion COVID-19 patients with pre-existing cerebrovascular disease have poor outcomes and extra precautions should be taken in managing such patients during the ongoing pandemic.
\end{abstract}

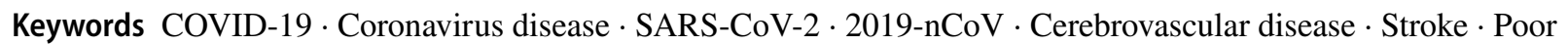
outcomes

Electronic supplementary material The online version of this article (https://doi.org/10.1007/s00415-020-10141-w) contains supplementary material, which is available to authorized users.

Preeti Malik

pmalik.ma@gmail.com

1 Department of Public Health, Icahn School of Medicine at Mount Sinai, 1 Gustave L. Levy Pl, New York, NY 10029, USA

2 Department of Neurology, Icahn School of Medicine at Mount Sinai, New York, NY, USA

3 Department of Neurology, Creighton University School of Medicine, Omaha, NE, USA

\section{Introduction}

Coronavirus disease-19 (COVID-19) is an ongoing pandemic with a progressively increasing number of cases and deaths worldwide. Resource allocation for critical cases is one of the challenging aspects of this pandemic, which warrants an urgent need to identify the patients at higher risk of severity and mortality. One study showed that patients with cerebrovascular diseases (CeVD) were associated with more severe infections [1]. Similar to Severe Acute Respiratory Syndrome (SARS) virus, some studies 
suggest a possible neurotropic mechanism of SARSCoV-2 virus which would provide a basis for neurological manifestations of COVID-19 [2]. The virus may enter the cerebral circulation, and the interaction of viral spike proteins with ACE2 receptors expressed in the capillary endothelium in the brain might damage the blood-brain barrier [3]. Several studies have been published on the epidemiological characteristics of COVID-19; however, data on patients with pre-existing CeVD are limited by a very small number of patients across these studies. In this article, we sought to carry out a pooled analysis of existing studies to evaluate the prevalence of CeVD and outcomes of COVID-19 patients with pre-existing CeVD.

\section{Methods}

\section{Endpoints}

The primary aim of this study was to evaluate prevalence and outcomes [intensive care unit (ICU) admission, mechanical ventilation, and mortality] of COVID-19 hospitalized patients with pre-existing cerebrovascular disease or stroke. Pre-existing cerebrovascular disease was defined as history of ischemic or transient ischemic attack irrespective to severity or disability status. COVID-19 confirmation was evaluated by combined findings of RT-PCR, serology, symptoms, and MRI chest in majority of those studies. The secondary aim of this study is to evaluate composite poor outcome associated with COVID-19 hospitalized patients with pre-existing cerebrovascular disease or stroke. The composite poor outcome is defined as intensive care unit (ICU) admission, oxygen saturation $<90 \%$, invasive mechanical ventilation (IMV) utilization, severe disease, and in-hospital mortality.

\section{Search strategy and selection criteria}

A systematic review was performed using MOOSE guidelines [4]. We searched PubMed, Web of Science, and Scopus for observational studies that described characteristics of COVID-19 from December 1, 2019 to April 30, 2020 following keyword/MESH terms: ((COVID-19 [Title/ Abstract]) OR coronavirus [Title/Abstract]) OR SARSCoV-2 [Title/Abstract] OR 2019-nCoV [Title/Abstract]. All studies describing epidemiology of COVID-19 were included. Literature other than observational studies, nonEnglish literature, non-full text, and animal studies were excluded. Flow diagram of literature search and study selection process is described in Supplemental file 1.

\section{Study selection}

Abstracts were reviewed, and articles were retrieved only if they mention CeVD or stroke as one of the pre-existing comorbidities. UP and PM independently screened all identified studies and assessed full texts to decide eligibility. Any disagreement was resolved through discussion with other reviewers (DS and AP).

\section{Data collection}

From the included studies, data relating to patient characteristics, outcomes of interest, and medical history of CeVD (as comorbidity) were collected using prespecified data collection forms by two authors (UP and PM), and discrepancies were solved by a discussion with DS. The following study characteristics were extracted: publication year, country of origin, sample size, age, history of CeVD as comorbidity, and outcomes. For secondary aim evolution, data of composite outcomes (poor vs non-poor) were collected.

\section{Assessment of risk of bias}

The Newcastle-Ottawa Quality Assessment Scale [5] and Cochrane Collaboration's tool [6] were used to evaluate the quality of the included studies and the risk of bias.

\section{Statistical analysis}

Primary aim was evaluated using comprehensive metaanalysis software, we calculated pooled prevalence, $95 \%$ confidence interval (95\% CI), and weights for CeVD and outcomes (events). Meta-regression was performed to evaluate the effects of pre-existing CeVD on outcomes of COVID-19 patients. Correlation coefficient $(r)$ and estimated odds ratio (OR) [ $e^{\wedge}$ coefficient] between preexisting CeVD and outcomes with corresponding $95 \%$ $\mathrm{CI}$ and quantifying magnitude of the relationship were pooled using a random-effects model. The proportion of total between-study variance explained by the model identified using analogous index $\left(R^{2}\right)$ and statistical heterogeneity across studies was reported using the $I^{2}$ statistics. Age-adjusted meta-regression was conducted to study the impact on incremental age. Review Manager version 5.4 (The Nordic Cochrane Centre, The Cochrane Collaboration, Copenhagen, Denmark) was used to evaluate secondary aim. The Maentel-Haenszel formula with randomeffects model was used to calculate OR along with its $95 \%$ CI to describe the relationship of pre-existing CeVD and composite outcomes of COVID-19 patients in each study. 
The $I^{2}$ statistic of $>75 \%$ was considered significant heterogeneity. $p<0.05$ was considered significant. Sensitivity analysis was also performed using the "leave-one-out method" to probe sources of heterogeneity.

\section{Results}

As of April 30, 2020, we included 11 observational studies with 4987 confirmed cases of COVID-19 patients detailing pre-existing CeVD. Of those 11 studies, 7 studies have reported ICU admissions (623/3901), and 8 studies have reported mechanical ventilation utilization (384/2196) and deaths (540/4240). Pooled prevalence of pre-existing CeVD comorbidity was 4.4\% [95\% CI 2.9-6.5\%; $p<0.001$; $244 / 4987$ patients], ICU admission was $19.3 \%$ [95\% CI 11.0-31.7\%; $p<0.001 ; 623 / 3901$ patients], mechanical ventilation was $22.9 \%$ [95\% CI $11.5-40.4 \% ; p=0.004$; $384 / 2196$ patients], and mortality was $14.3 \%$ [95\% CI 7.2-26.4\%; $p<0.0001 ; 540 / 4240$ patients] (Table 1).

\section{Meta-regression}

Meta-regression random effects models quantified the study level impact of pre-existing CeVD in COVID-19 patients on ICU admission, mechanical ventilation utilization, and mortality. Amongst COVID-19 patients with pre-existing CeVD, the unadjusted meta regression models showed strong association with ICU admission [r: 0.43 ; OR: $1.54 ; 95 \%$ CI $1.25-1.62 ; I^{2}$ : $94.5 \%$; $p=0.0001]$, mechanical ventilation $[r: 0.28$; OR: 1.32 ; 95\% CI: $\left.1.13-1.55 ; I^{2}: 91.3 \% ; p=0.005\right]$, and mortality $[r$ : 0.37; OR: 1.45 ; 95\% CI $\left.1.22-1.72 ; I^{2}: 95.9 \% ; p<0.0001\right]$ (Table 2).

Similarly, in age-adjusted meta-regression analysis, preexisting CeVD among COVID-19 patients was associated with higher estimated odds of ICU admission [ $r$ : 0.60; OR: $1.82 ; 95 \%$ CI $\left.1.25-2.69 ; I^{2}: 93.8 \% ; p=0.0021\right]$, mechanical ventilation $\left[r\right.$ : 0.29 ; OR: $1.33 ; 95 \%$ CI $1.09-1.63 ; I^{2}$ : $93.4 \% ; p=0.0038]$, and mortality [ $r$ : 0.35 ; OR: $1.42 ; 95 \%$ CI $\left.1.14-1.77 ; I^{2}: 96.1 \% ; p=0.0018\right]$. Figure 1a-c suggests a significant increase between log odds of poor outcomes and pre-existing CeVD in COVID-19 patients. Sensitivity analysis showed that the removal of any single study did not change the significance of the results. Additionally, overall studies had moderate risk of bias (Supplemental file 2). The heterogeneity analysis of the age-adjusted models of ICU admission, mechanical ventilation, and mortality showed 93.8\%, 93.4\% and $96.1 \%$ dispersion observed between studies, respectively, and $0 \%, 57 \%$ and $32 \%$ of such variance was explained by the models, respectively.

\section{Meta-analysis}

A total of 9 studies reported data on pre-existing CeVD and binary composite outcomes giving a total sample size of 3603 COVID-19 hospitalizations, the pooled prevalence of pre-existing CeVD was $4.3 \%$ (155/3603). In patients with poor outcomes, the pooled prevalence of pre-existing CeVD was $7.46 \%$ (83/1113). Meta-analysis of all nine studies showed that COVID-19 patient with pre-existing CeVD had higher odds of poor outcomes compared to better outcomes with a pooled OR of 2.67 (95\% CI 1.75-4.06; $p=0.03$ ), with minimal heterogeneity between studies $\left(I^{2}=12 \%\right.$; $\left.\mathrm{Tau}^{2}=0.05 ; \mathrm{Chi}^{2}=9.10 ; p \leq 0.00001\right)$ (Fig. 2). Leave-oneout method sensitivity analysis did not change odds ratio.

\section{Discussion}

In our analysis, pooled prevalence of pre-existing CeVD was $\sim 4.4 \%$ among confirmed cases of COVID- 19 . The pooled prevalence of pre-existing CeVD was $7.46 \%$ in among COVID-19 patients with poor outcomes. We found that pre-existing CeVD was significantly associated with increased risk of ICU admission and mechanical ventilation utilization in patients with COVID-19. In meta-analysis, preexisting CeVD had 2.67-fold high risk of poor outcomes. Our findings are supported by recently published pooled analysis, where authors have reported that CeVD was associated with approximate 2.5 -fold increased disease severity in COVID-19 patients [7]. Furthermore, we found a significant incremental correlation between pre-existing CeVD and mortality in COVID-19 patients. CeVD is associated with high mortality, morbidity, and increased healthcare costs in USA [8]. Previous studies have reported that SARS and Middle East Respiratory Syndrome patients with pre-existing CeVD were not only at higher risk of poor outcomes, but also increased health care utilization $[9,10]$. The exact pathophysiology behind role of pre-existing CeVD and poor outcome is still to be determined but such patients are at high risk due to underlying concurrent conditions such as old age, hypertension, cardiovascular disorders like arrythmia, diabetes, low immunity-related [11] COVID-19 severity, etc. Such patients are also at risk of developing cardio-embolic events [12] secondary to viral and bacterial infection or new cerebrovascular events secondary to thrombotic microangiopathy [13, 14], hypercoagulability leading to macro- and micro-thrombi formation in the vessels, hypoxic injury, disruption of the blood and blood brain barrier [15].

The national data from RAPID AI, a commercially available automated acute stroke screening software, have shown 39\% reduction in acute emergency department (ED) stroke evaluation during a 29-day pre-pandemic period in February 2020 to a 2-week stretch of March 26 to April 8 


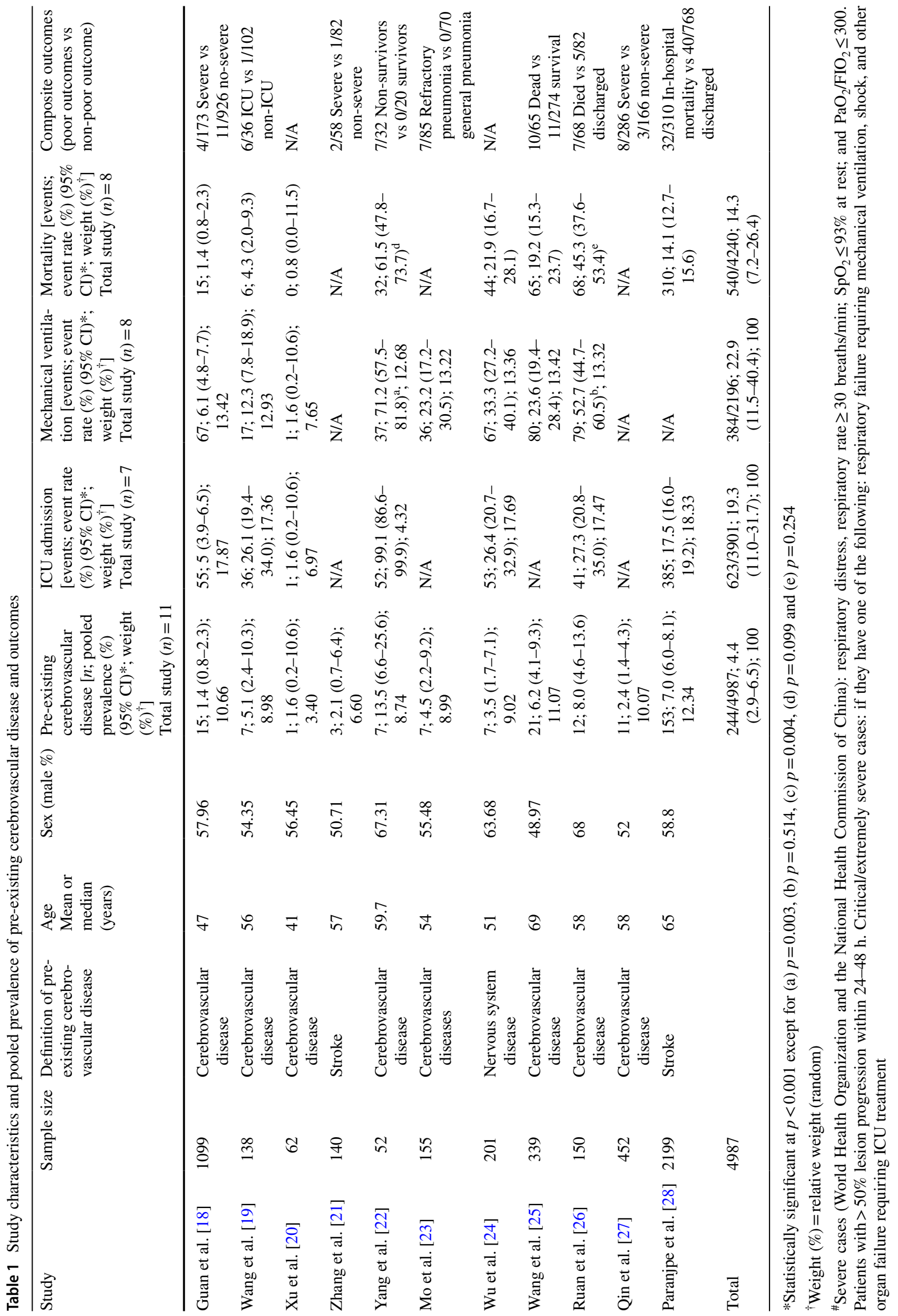


Table 2 Meta-regression showing association of pre-existing cerebrovascular disease and outcome

\begin{tabular}{|c|c|c|c|c|c|}
\hline & $\begin{array}{l}\text { Correlation coefficient } \\
\text { between CeVD and out- } \\
\text { comes }(95 \% \mathrm{CI}) ; p \text { value }\end{array}$ & $\begin{array}{l}\text { Odds ratio } \\
e^{\wedge} \text { coefficient } \\
(95 \% \mathrm{CI})\end{array}$ & $\begin{array}{l}\text { Quantifying magni- } \\
\text { tude of the relationship } \\
\ln (\text { outcome rate })=\text { inter- } \\
\text { cept }+\mathrm{m}(X)\end{array}$ & $\begin{array}{l}\text { Analogous } \\
\text { index }\left(R^{2}\right)\end{array}$ & $\begin{array}{l}\text { Heterogeneity* } I^{2}(\%) ; \\
\text { Cochran's Qmodel; Tau } \\
\text { unexplained }\end{array}$ \\
\hline $\begin{array}{l}\text { ICU admission (unad- } \\
\text { justed) }\end{array}$ & $0.43(0.22-0.65) ; 0.0001$ & $1.54(1.25-1.62)$ & $-3.65+0.43(\mathrm{CeVD} \%)$ & 0.07 & $94.46 ; 15.48 ; 0.57$ \\
\hline $\begin{array}{l}\text { ICU admission (age- } \\
\text { adjusted) }\end{array}$ & $0.60(0.22-0.99) ; 0.0021$ & $1.82(1.25-2.69)$ & $\begin{array}{l}-0.18+0.60 \\
\quad(\mathrm{CeVD} \%)+0.60 \text { (age in } \\
\text { years) }\end{array}$ & 0.00 & $93.82 ; 15.13 ; 0.78$ \\
\hline $\begin{array}{l}\text { Mechanical ventilation } \\
\text { (unadjusted) }\end{array}$ & $0.28(0.12-0.44) ; 0.0005$ & $1.32(1.13-1.55)$ & $-2.65+0.28(\mathrm{CeVD} \%)$ & 0.38 & $91.28 ; 12.19 ; 0.40$ \\
\hline $\begin{array}{l}\text { Mechanical ventilation } \\
\text { (age-adjusted) }\end{array}$ & 0.29 (0.09-0.49); 0.0038 & $1.33(1.09-1.63)$ & $\begin{array}{l}-3.53+0.29 \\
(\text { CeVD\% })+0.01 \text { (age in } \\
\text { years) }\end{array}$ & 0.57 & $93.43 ; 14.74 ; 0.57$ \\
\hline Mortality (unadjusted) & $0.37(0.20-0.54) ;<0.0001$ & $1.45(1.22-1.72)$ & $-4.30+0.37(\mathrm{CeVD} \%)$ & 0.40 & $95.93 ; 18.00 ; 0.65$ \\
\hline Mortality (age-adjusted) & $0.35(0.13-0.57) ; 0.0018$ & $1.42(1.14-1.77)$ & $\begin{array}{l}-5.01+0.35 \\
(\mathrm{CeVD} \%)+0.02 \text { (age in } \\
\text { years) }\end{array}$ & 0.32 & $96.11 ; 16.46 ; 0.73$ \\
\hline
\end{tabular}

Meta-regression models are based on random effects

$X$ pre-existing cerebrovascular disease

*Statistically significant at $p<0.001$
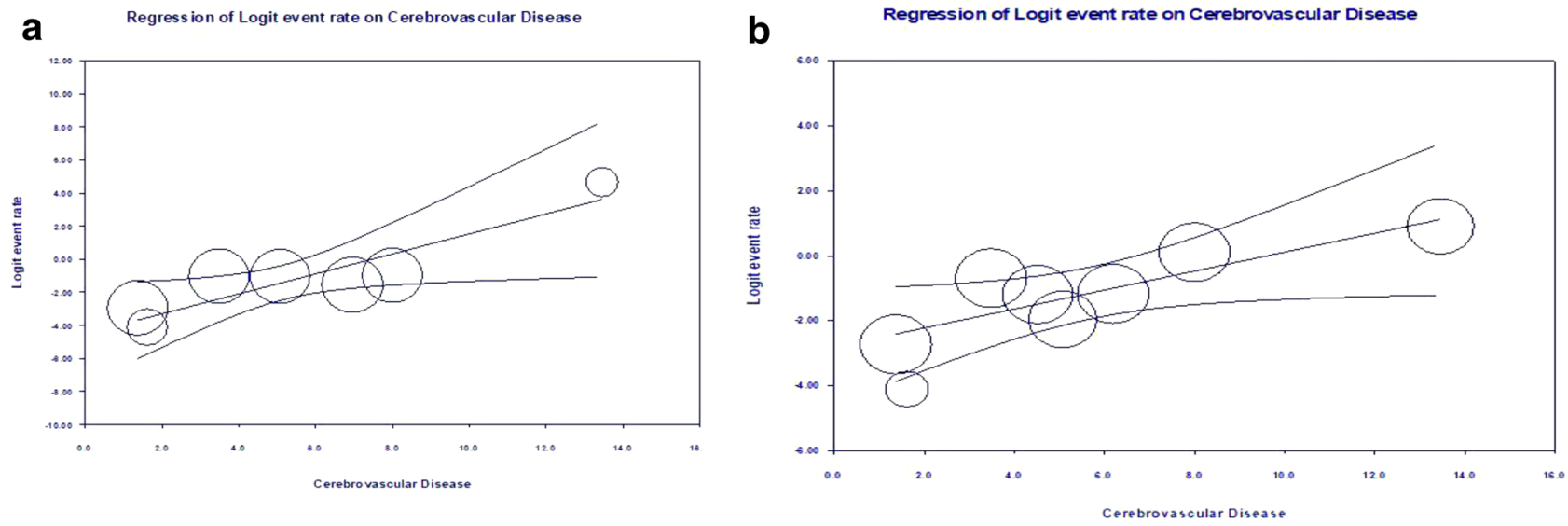

C Regress ion of Logit event rate on Cerebrovas cular Disease

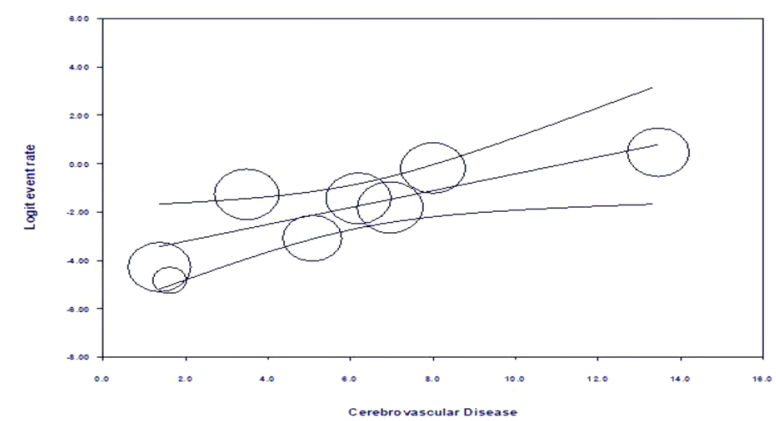

Fig. 1 a Cerebrovascular disease and ICU admission. b Cerebrovascular disease and mechanical ventilation. c Cerebrovascular disease and mortality 


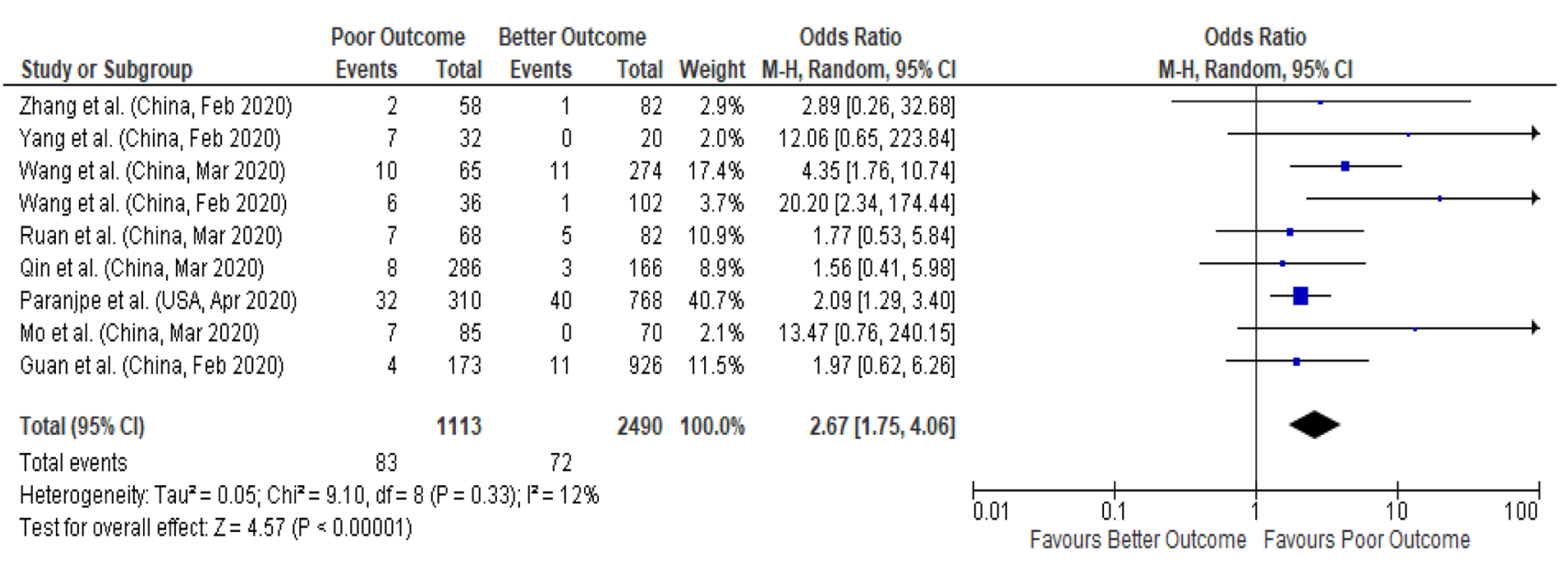

Fig. 2 Forest plot of pre-existing cerebrovascular disease and composite outcome

in 856 hospitals across the USA [16]. This reduction may be explained by enforced social distancing practice due to pandemic. Such behavior may exclude asymptomatic or mildly symptomatic COVID-19 individuals from minor stroke symptom evaluation in ED who potentially could be at higher risk of stroke recurrence and poor outcome. Therefore, in the setting of limited healthcare resources in the current COVID-19 pandemic, identifying high risk patients will help to prioritize and individualize treatment protocols based on severity of pre-existing disease and predominant organ involvement [17].

\section{Strength and limitations}

To our knowledge, this is the large population study that shows association between pre-existing CeVD and outcomes, especially mortality. Our findings may provide early insights into designing models for early identification of high-risk patients and prioritizing their treatment based on disease severity, which will help in prudent use of limited healthcare resources during this pandemic. A limitation of this study is missing details on type of CeVD or stroke severity, stroke disability (NIHSS or mRS), types, and medications. In addition, we have analyzed only COVID-19 hospitalized patients, so prediction of outcomes amongst COVID-19 positive with mild-to-moderate symptoms are unknown. Due to nonidentical effects being estimated in studies analyzed in our meta-regression, our study has high heterogeneity which we tried to justify using random-effects model and sensitivity analysis. Moreover, meta-regression analysis will always be subject to the risk of ecological fallacy, as we attempt to make inferences about individuals using study-level information. However, our meta-analysis had no significant heterogeneity and also showed higher odds of poor outcomes in COVID-19 patients with preexisting CeVD. More observational studies, adjusted for risk factors and comorbidities with larger sample sizes dedicated to evaluating stroke burden, are needed to confirm our findings.

\section{Conclusion}

We found that COVID-19 patients with preexisting CeVD have poorer outcomes including increased ICU admission, mechanical ventilation utilization and mortality. However, large observational studies with reported outcomes are needed to validate these findings and evaluate the role of COVID-19 in developing new CeVD and stroke due to its pro-inflammatory and hypercoagulation states. Despite the limitations of our study, we advocate that clinicians should take extra precautions for patients with a history of cerebrovascular diseases during the ongoing pandemic.

Author contributions Conceptualization: UP. Methodology: UP, PM. Formal analysis and investigation: UP, PM. Writing—original draft preparation: UP, PM, DS, AP. Writing-review and editing: MC, VJ. Funding acquisition: None. Resources: VJ. Supervision: VJ.

Funding The study had no internal or external funding source.

Data availability The data are deidentified and collected from the studies published online, it will be made available upon request.

Code availability Codes used for analysis will be available upon request. 


\section{Compliance with ethical standards}

Conflicts of interest We declare no competing interests. The authors report no disclosures relevant to the manuscript.

Ethical approval Though this article does not contain any studies with direct involvement of human participants or animals performed by any of the authors, all procedures performed in studies involving human participants were in accordance with the ethical standards of the institutional and/or national research committee and with the 1964 Helsinki Declaration and its later amendments or comparable ethical standards.

Consent to participate The data used in this study are publicly available and de-identified database thus informed consent or IRB approval was not needed for this study.

\section{References}

1. Mao L, Jin H, Wang M, Hu Y, Chen S, He Q, Chang J, Hong C, Zhou Y, Wang D, Miao X, Li Y, Hu B (2020) Neurologic manifestations of hospitalized patients with coronavirus disease 2019 in Wuhan, China. JAMA Neurol. https://doi.org/10.1001/jaman eurol.2020.1127

2. Li Y-C, Bai W-Z, Hashikawa T (2020) The neuroinvasive potential of SARS-CoV2 may play a role in the respiratory failure of COVID-19 patients. J Med Virol 92(6):552-555. https://doi. org/10.1002/jmv. 25728

3. Baig AM, Khaleeq A, Ali U, Syeda H (2020) Evidence of the COVID-19 virus targeting the CNS: tissue distribution, host-virus interaction, and proposed neurotropic mechanisms. ACS Chem Neurosci 11(7):995-998. https://doi.org/10.1021/acschemneu ro.0c00122

4. Stroup DF, Berlin JA, Morton SC, Olkin I, Williamson GD, Rennie D, Moher D, Becker BJ, Sipe TA, Thacker SB (2000) Metaanalysis of observational studies in epidemiology: a proposal for reporting. Meta-analysis Of Observational Studies in Epidemiology (MOOSE) group. JAMA 283(15):2008-2012. https://doi. org/10.1001/jama.283.15.2008

5. GA Wells, B Shea, D O'Connell, J Peterson, V Welch, M Losos, P Tugwell (2020) The Newcastle-Ottawa Scale (NOS) for assessing the quality of nonrandomised studies in meta-analyses. Professor GA Wells, Department of Epidemiology and Community Medicine. https://www.ohri.ca/programs/clinical_epidemiology/oxfor d.asp

6. Higgins JPT, Thomas J, Chandler J, Cumpston M, Li T, Page MJ, Welch VA (2019) Cochrane handbook for systematic reviews of interventions, 2nd edn. John Wiley \& Sons, Chichester

7. Aggarwal G, Lippi G, Michael Henry B (2020) Cerebrovascular disease is associated with an increased disease severity in patients with Coronavirus Disease 2019 (COVID-19): a pooled analysis of published literature. Int J Stroke. https://doi.org/10.1177/17474 93020921664

8. Virani SS, Alonso A, Benjamin EJ, Bittencourt MS, Callaway CW, Carson AP, Chamberlain AM, Chang AR, Cheng S, Delling FN, Djousse L, Elkind MSV, Ferguson JF, Fornage M, Khan SS, Kissela BM, Knutson KL, Kwan TW, Lackland DT, Lewis TT, Lichtman JH, Longenecker CT, Loop MS, Lutsey PL, Martin SS, Matsushita K, Moran AE, Mussolino ME, Perak AM, Rosamond WD, Roth GA, Sampson UKA, Satou GM, Schroeder EB, Shah SH, Shay CM, Spartano NL, Stokes A, Tirschwell DL, VanWagner LB, Tsao CW (2020) heart disease and stroke statistics-2020 update: a report from the American Heart Association. Circulation 141(9):e139-e596. https://doi.org/10.1161/cir.000000000000075 7

9. Chen CY, Lee CH, Liu CY, Wang JH, Wang LM, Perng RP (2005) Clinical features and outcomes of severe acute respiratory syndrome and predictive factors for acute respiratory distress syndrome. J Chin Med Assoc JCMA 68(1):4-10. https://doi. org/10.1016/s1726-4901(09)70124-8

10. Lee SY, Khang YH, Lim HK (2019) Impact of the 2015 middle east respiratory syndrome outbreak on emergency care utilization and mortality in South Korea. Yonsei Med J 60(8):796-803. https ://doi.org/10.3349/ymj.2019.60.8.796

11. Steardo L, Steardo L Jr, Zorec R, Verkhratsky A (2020) Neuroinfection may contribute to pathophysiology and clinical manifestations of COVID-19. Acta Physiol. https://doi.org/10.1111/ apha. 13473

12. Grau AJ, Buggle F, Becher H, Zimmermann E, Spiel M, Fent T, Maiwald M, Werle E, Zorn M, Hengel H, Hacke W (1998) Recent bacterial and viral infection is a risk factor for cerebrovascular ischemia: clinical and biochemical studies. Neurology 50(1):196-203. https://doi.org/10.1212/wnl.50.1.196

13. Barton LM, Duval EJ, Stroberg E, Ghosh S, Mukhopadhyay S (2020) COVID-19 autopsies, Oklahoma, USA. Am J Clin Pathol 153(6):725-733

14. Fox SE, Akmatbekov A, Harbert JL, Li G, Brown JQ, Vander Heide RS (2020) Pulmonary and cardiac pathology in Covid-19: the first autopsy series from New Orleans. medRxiv. https://doi. org/10.1101/2020.04.06.20050575

15. Wu Y, Xu X, Chen Z, Duan J, Hashimoto K, Yang L, Liu C, Yang C (2020) Nervous system involvement after infection with COVID-19 and other coronaviruses. Brain Behav Immun. https ://doi.org/10.1016/j.bbi.2020.03.031

16. Kansagra AP, Goyal MS, Hamilton S, Albers GW (2020) Collateral effect of Covid-19 on stroke evaluation in the United States. N Engl J Med. https://doi.org/10.1056/NEJMc2014816

17. Emanuel EJ, Persad G, Upshur R, Thome B, Parker M, Glickman A, Zhang C, Boyle C, Smith M, Phillips JP (2020) Fair allocation of scarce medical resources in the time of Covid-19. N Engl J Med. https://doi.org/10.1056/NEJMsb2005114

18. Guan W-j, Ni Z-y, Hu Y, Liang W-h, Ou C-q, He J-x, Liu L, Shan H, Lei C-1, Hui DSC, Du B, Li L-j, Zeng G, Yuen K-Y, Chen R-c, Tang C-1, Wang T, Chen P-y, Xiang J, Li S-y, Wang J-1, Liang Z-j, Peng Y-x, Wei L, Liu Y, Hu Y-h, Peng P, Wang J-m, Liu J-y, Chen Z, Li G, Zheng Z-j, Qiu S-q, Luo J, Ye C-j, Zhu S-y, Zhong $\mathrm{N}-\mathrm{s}$ (2020) Clinical characteristics of coronavirus disease 2019 in China. N Engl J Med. https://doi.org/10.1056/NEJMoa2002032

19. Wang D, Hu B, Hu C, Zhu F, Liu X, Zhang J, Wang B, Xiang H, Cheng Z, Xiong Y, Zhao Y, Li Y, Wang X, Peng Z (2020) Clinical characteristics of 138 hospitalized patients with 2019 novel coronavirus-infected pneumonia in Wuhan, China. JAMA 323(11):1061-1069. https://doi.org/10.1001/jama.2020.1585

20. Xu X-W, Wu X-X, Jiang X-G, Xu K-J, Ying L-J, Ma C-L, Li S-B, Wang H-Y, Zhang S, Gao H-N, Sheng J-F, Cai H-L, Qiu Y-Q, Li L-J (2020) Clinical findings in a group of patients infected with the 2019 novel coronavirus (SARS-Cov-2) outside of Wuhan, China: retrospective case series. BMJ 368:m606. https://doi. org/10.1136/bmj.m606

21. Zhang JJ, Dong X, Cao YY, Yuan YD, Yang YB, Yan YQ, Akdis CA, Gao YD (2020) Clinical characteristics of 140 patients infected with SARS-CoV-2 in Wuhan, China. Allergy. https:// doi.org/10.1111/all.14238

22. Yang X, Yu Y, Xu J, Shu H, Xia J, Liu H, Wu Y, Zhang L, Yu Z, Fang M, Yu T, Wang Y, Pan S, Zou X, Yuan S, Shang Y (2020) Clinical course and outcomes of critically ill patients with SARS-CoV-2 pneumonia in Wuhan, China: a single-centered, retrospective, observational study. Lancet Respir Med. https://doi. org/10.1016/s2213-2600(20)30079-5 
23. Mo P, Xing Y, Xiao Y, Deng L, Zhao Q, Wang H, Xiong Y, Cheng Z, Gao S, Liang K, Luo M, Chen T, Song S, Ma Z, Chen X, Zheng R, Cao Q, Wang F, Zhang Y (2020) Clinical characteristics of refractory COVID-19 pneumonia in Wuhan, China. Clin Infect Dis. https://doi.org/10.1093/cid/ciaa270

24. Wu C, Chen X, Cai Y, Xia J, Zhou X, Xu S, Huang H, Zhang L, Zhou X, Du C, Zhang Y, Song J, Wang S, Chao Y, Yang Z, Xu J, Zhou X, Chen D, Xiong W, Xu L, Zhou F, Jiang J, Bai C, Zheng J, Song Y (2020) Risk factors associated with acute respiratory distress syndrome and death in patients with coronavirus disease 2019 pneumonia in Wuhan, China. JAMA Intern Med. https://doi. org/10.1001/jamainternmed.2020.0994

25. Wang L, He W, Yu X, Hu D, Bao M, Liu H, Zhou J, Jiang H (2020) Coronavirus disease 2019 in elderly patients: characteristics and prognostic factors based on 4-week follow-up. J Infect. https://doi.org/10.1016/j.jinf.2020.03.019

26. Ruan Q, Yang K, Wang W, Jiang L, Song J (2020) Correction to: clinical predictors of mortality due to COVID-19 based on an analysis of data of 150 patients from Wuhan, China. Intensive Care Med. https://doi.org/10.1007/s00134-020-06028-Z

27. Qin C, Zhou L, Hu Z, Zhang S, Yang S, Tao Y, Xie C, Ma K, Shang K, Wang W, Tian DS (2020) Dysregulation of immune response in patients with COVID-19 in Wuhan, China. Clin Infect Dis. https://doi.org/10.1093/cid/ciaa248

28. Paranjpe I, Russak A, De Freitas JK, Lala A, Miotto R, Vaid A, Johnson KW, Danieletto M, Golden E, Meyer D, Singh M, Somani S, Manna S, Nangia U, Kapoor A, O'Hagan R, O'Reilly PF, Huckins LM, Glowe P, Kia A, Timsina P, Freeman RM, Levin MA, Jhang J, Firpo A, Kovatch P, Finkelstein J, Aberg JA, Bagiella E, Horowitz CR, Murphy B, Fayad ZA, Narula J, Nestler EJ, Fuster V, Cordon-Cardo C, Charney DS, Reich DL, Just AC, Bottinger EP, Charney AW, Glicksberg BS, Nadkarni G (2020) Clinical characteristics of hospitalized covid-19 patients in New York City. Nature. https://doi.org/10.1101/2020.04.19.20062117 